\title{
Why Patients Use Traditional Medicine in Burn
}

\author{
Mohammad Qtait, MSN, RN *1, Farid Abu Liel MSN, RN ${ }^{2}$, Salwa Massad PHD ${ }^{3}$, Ayman Asfour RN ${ }^{4}$ \\ ${ }^{1}$ Arab American University, Palestine PhD Nursing Student \\ ${ }^{2}$ Faculty of Nursing, Arab American University, Palestine \\ ${ }^{3}$ Research Unit, Palestinian National Institute of Public Health, Ramallah, Palestine \\ ${ }^{4}$ Ministry of Health Palestine
}

*Corresponding author: Mohammad Qtait; mohamadtaha98@hotmail.com

Received 06 November 2021;

Accepted 19 November 2021;

Published 22 November 2021

\begin{abstract}
Background: People from different cultural and thinking backgrounds have used different forms of Traditional Medicine as a means to managing their diseases or trauma. Objective: To know why people use the traditional medicine in burn. Methods: Use questionnaire and divided tow section first demographic variable second section contain 13 items and divided three subsection to know why people go traditional therapy (1) they are dissatisfied in some way with conventional treatment; (2) the patients' values, customs and (3) Beliefs and think. Additional predictor variables explored included demographics. Design : Cross-sectional study was conducted in main governmental hospital contain burn unite south of Palestine during the one year January 2020 to 31 December 2020 with burns and use traditional therapy admitted to burn unite any percent. Result: admitted to burn unite in Hebron government hospital 290 patient in 2020 with percent $29 \%$ of admission use traditional therapy. The study participants were; $53.0 \%$ males, child and more than $50 \%$, and $46.1 \%$ from participant use alternative medicine before. According to information to use $22 \%$ from participants, know from friends, $53.3 \%$ know from internet, 16.8 form media as radio and TV, $15 \%$ know from family, $7 \%$ from participants know from health care worker as physician and nurses, the main dissatisfaction with conventional medicine with percent $53 \%$, the second cause the patients' values, customs with percent $46 \%$, the third cause Beliefs and think $45 \%$. Conclusion: For use can, summary first for burn is convinced that traditional therapy is best than convention medicine, due not leave scar and rapid healing based on experiment in. Society and elderly. Another explanation for using traditional medicine in burn think as philosophy no side effect for medication the mixture that uses from nature not contain chemical material, and thought the body it's myself can use anything to treatment the body.
\end{abstract}

Keyword: Traditional Medicine, Burn, Complementary Medicine, Palestine

\section{Introduction}

A significant number of people in Palestine utilize traditional medicine. Among Palestinian 20\% from admission to burn, unite after used a traditional medicine (M. Qtait \& Asfour). Palestine people use traditional medicine in the first aid of burn with percent 40\% (M. Qtait, Alekel, \& Asfour, 2019).

The World Health Organization (WHO) defines traditional therapy as the "sum total of the knowledge, skill, and practices based on the theories, beliefs, and experiences indigenous to different cultures, whether explicable or not, used in the maintenance of health, as well as in the prevention, diagnosis, improvement or treatment of physical and mental illness."

Alternative medicine is 'not in the traditional field of medicine.' It might be based rather than scientific conclusions on historical or cultural traditions. Additional or alternative terms in various places are used interchangeably with standard therapy (Tabish, 2008). Various health practices that are not part of the legacy of the country and not part of the prevailing medical system are mentioned. There are 10 to 52 percent of individuals in
Western Industrialized Countries using CAM.(Bishop, Yardley, \& Lewith, 2008).

More than 90 per cent of the fatal brand in emerging or low-income countries was reported by the World Health Organization. Palestine is a youthful country, with $36.9 \%$ under 14 years of age (Ahuja \& Bhattacharya, 2004). In the West Bank, there are around 7,600 burn wounds yearly. Among those, more than $65 \%$ are children (Palestine, 2018). Most burn wounds, almost $72 \%$, are a result of singe burns from hot water, and almost $21 \%$ are flame-related $(\mathrm{MoH}, 2013)$. Ordinarily, the sort of injury is related to the age of the persistent, as children are more likely to induce burn wounds, and flame-related wounds are more likely to happen in grown-ups (MoH, 2013).

Optimal burn treatment demands a particular multidisciplinary approach since the burn therapy team and strong cooperation between the members depend on the physiotherapy of the nursery, the doctor, the diet and other good outcomes for the patient. (Greenfield, 2010.). The application of traditional therapy is rhetorical and might include a health risk. All types of plants, animals and minerals used in traditional contexts might be well 
recognized to cause to serious adverse reactions. (De Smet, 1991). Along with education and poor health, most alternative health care clients seem less deceptive of standard therapy than they do, as they are more compatible with their own values, beliefs and health and life philosophy. (Astin, 1998).

The first study in Palestine to know why go traditional therapy to develop health sector. According to the researcher experience in the burn unit, he found that the care of burn and give perfect care less stay on hospital, proper treatment of burn and avoided traditional therapy All of these factors outcome of burn, affect the burn healing process and the curing time.

In Palestine study by Patient's reports to tertiary center late after infection appear. A total of 50 burn cases were coming to burn unite in 2019 infected burn post traditional therapy the study period (M. Qtait \& Asfour).

Most of literature talk about alternative medicine that has used in the treatment in different diseases and the benefit of alternative therapy some article talk about why use alternative medicine and make theory as (Ray.1998). No alternative medicine in Palestine literature and why, only medicinal plant book in Palestine. The research hypothesis less satisfaction with traditional medicine is reported. Traditional medicine is considered as more consistent with the values, customs and nature of health and disease of the patients. The traditional medicines are seen as more compatible with the patients' think and beliefs regarding the nature. The research question Why patient use traditional therapy in Palestine?. What are the characteristics of traditional therapy for burn use in this population? What are the sources of information for traditional therapy for burn use? The main goal of the study To investigate possible predictors of people yse traditional therapy in burn.

\section{Method}

\subsection{Study design}

This study was based on quantitative method, and a cross-sectional study containing burns south of Palestine was performed at major government hospital from one year January 2020 to the year 31 December 2020.

\section{2 study area}

The study was conducted in south of west bank (Jericho, east jureslum, Bethlehem, and hebron 2.3 Population Study.

Population All patient coming after use traditional medicine and admission to burn units in hebron government hospital 270 patient from south of west bank (Jericho, east jureslum, Bethlehem, and hebron).

\subsection{Inclusion and exclusion criteria}

Inclusion criteria: All patients allowed to burn from the south of the west bank to join the hospital in Hebron in 2020, Requirement to take part in the study.

Exclusion criteria: who patient burn and not use alternative medicine, who not willingness to participate in the study.

\subsection{Construction of data collection Instrument}

After scanning related research and literature, the survey questionnaire was created by the study investigator on why alternative medicine and Ray are used (Ray, 1997). Questionnaire the legitimacy of the content was guaranteed by a thorough literature research and by conversation in this subject with a number of professionals. The surveys were made in Arabic; questions were structured in such a way that simple Arabic phrases could be understood easily. When preparing the questionnaire, difficult technical words were avoided. The questionnaire was developed into two main sections covering; the demographic information (gender, age, place of live, burn before, income, who decided to go alternative medicine). Second section contain 13 items divided in three subsection, the first subsection 6 seven items related to dissatisfaction with conventional medicine, second subsection related 4 items values, customs, beliefs, third subsection 3 items related beliefs and think. The questionnaires items were arranged into Yes and No.

\subsection{Validity and Reliability of the tool}

\subsubsection{Validity}

The tool utilized in this investigation was built by the researchers and backed by prior studies (Ray, 1997). The validity of the content relates to the relevance of the questions to the subject. The validity of tools containing all essential ideas pertinent to the research theme were censured in this study. The questions were asked why alternative medicines were used.

\subsubsection{Reliability}

Questionnaire reliability guaranteed in pilot research and assessed by means of the Coefficient alpha, normally between $(0.00$ and 1.00), where the highest value reflects a greater internal consistency of the questionnaires. Theme of this questionnaire (Polit \& Beck, 2012). The reliability of Cronbach alpha achieved was (0.829) for the total scale suggesting a strong consistency of the tests.

\subsection{Pilot Study}

The purpose of the pilot research was to: estimate the time necessary to collect the data, to establish the questionnaires, to acquire clarity and adequacy, and to identify impediments to the collection of the data.

On 15 patients from outside usage of traditional medicine, the device was pilot tested. The results indicated that the alpha coefficient for the reliability of the questionnaire was (0.82) and the responses demonstrated consistency in comprehending issues where no modifications or changes were required.

\subsection{Data analysis}

Using the Social Science Statistical Package software (SPSS V.23 Computer Software), for descriptive and inferential statistics, the data compiled were then modified, inputted and analysed. The distribution of the research variables was utilized with frequencies. The statistical test of one-way ANOVA was also employed. The researchers and statistics have used Alpha Cronbach in this study to assess the reliability of the questionnaire and to test for the dependability of the data collecting tool.

\subsection{Ethical consideration and accessibility}

Ethical approval was obtained from the Arab American University before starting data collection. Ethics provide norms and expectations of behavior on the best way to conduct all players. The subject was told of the objective of the study via a permission (attached to the questionnaire), secured private and sponsored form. Moreover, they were told about their right, during the study through informed agreement, to decline or withdraw from any questionnaire at any moment.

\subsection{Independent Variables}

The independent variables considered possible predictors of traditional medicine health care use. Since constructs like" 
- Dissatisfaction: Patients are dissatisfied with conventional treatment because it has been ineffective leave scar post burn, has traditional medicine because of the good reputation, rapid healing than convetional medicine, were better than medicine no clinics near the home or too costly.

- The patients' values, custms: advice of the elderly, customs and traditions in society. prevailing culture in society, because of the experience of the therapist, where the methods of treatment are inherited from the ancestors

- Beliefs regarding the nature and meaning of health and illness. Freedom of action in my body, traditional medicine Maintain privacy

- Demographic factors

\subsection{Dependent Variable}

Dependent variable, primary reliance on alternative medicine, a dichotomous measure defined by those respondents who reported using primarily alternative therapies to treat burn.

The study participants were; $53.0 \%$ males with more than $25.5 \%$ child and more than $50 \%$, and $46.1 \%$ from participant use alternative medicine before, for living $46.1 \%$ living in Village, in City 36.3\% and Bedouins $11.8 \%$.

According to information to use $22 \%$ from participants, know from friends, $53.3 \%$ know from internet, 16.8 form media as radio and TV, $15 \%$ know from family, $7 \%$ from participants know from health care worker as physician and nurses, the median of age 12 years.

\begin{tabular}{|c|l|l|}
\hline & Why use traditional therapy in burn & Yes \\
\hline & Disatisfaction with conventional medicine & \\
\hline 1 & I went to the traditional medicine because of the good reputation & $54 . \%(54)$ \\
\hline 2 & I went to the traditional medicine because it did not leave scar post burn & $70 \%(70)$ \\
\hline 3 & I went to traditional medicine because of the lack of trust in doctors & $51 \%(51)$ \\
\hline 4 & I went to traditional medicine because it's rapid healing & $67 . \%(67)$ \\
\hline 5 & I went to traditional medicine because I thought they were better than medicine and doctors & $57 \%(57)$ \\
\hline 6 & I went to traditional medicine because of the high cost of doctors & $54 \%(54)$ \\
\hline 7 & I went to the traditional medicine because there are no clinics near the home & $18 \%(18)$ \\
\hline & The patients' values, custms & $45 . \%(45)$ \\
\hline 8 & I went to traditional medicine because of the advice of the elderly & $55 . \%(55)$ \\
\hline 9 & I went to traditional medicine because of customs and traditions & $45 . \%(45)$ \\
\hline 10 & I went to traditional medicine because of the prevailing culture in society & $45 \%(45)$ \\
\hline 11 & $\begin{array}{l}\text { I went to traditional medicine because of the experience of the therapist, where the methods of treatment are } \\
\text { inherited from the ancestors }\end{array}$ & \\
\hline & Beliefs and think & $54 \%(54)$ \\
\hline 12 & I went to the traditional medicine Freedom of action in my body & $36 . \%(36)$ \\
\hline 13 & I went to the traditional medicine Maintain privacy & \\
\hline
\end{tabular}

From table above see the main cause use traditional therapy because I went to the traditional medicine because it did not leave scar post burn with percent $70 \%$ said yes, another cause to use traditional medicine because it's rapid healing with percent $70 \%$, the third main cause traditional medicine because I thought they were better than medicine and doctors with percent $57 \%$, the lower causes use traditional medicine because there are no clinics near the home with percent $18 \%$. According to the patients' values, custms use traditional medicine because of customs and traditions in the society with percent $55 \%$. According to Beliefs and think use traditional medicine Freedom of action in my body 54\%One way ANOVA Test social statues and living and job with why use traditional therapy.

\begin{tabular}{|c|c|c|c|c|c|c|}
\hline \multicolumn{7}{|l|}{ ANOVA } \\
\hline & & Sum of Squares & df & Mean Square & $\mathbf{F}$ & Sig. \\
\hline \multirow[t]{3}{*}{ Social staies } & Between Groups & 55.594 & 13 & 4.276 & 1.377 & .187 \\
\hline & Within Groups & 270.188 & 87 & 3.106 & & \\
\hline & Total & 325.782 & 100 & & & \\
\hline \multirow[t]{3}{*}{ Living } & Between Groups & 15.339 & 13 & 1.180 & 1.382 & .185 \\
\hline & Within Groups & 74.304 & 87 & .854 & & \\
\hline & Total & 89.644 & 100 & & & \\
\hline \multirow[t]{3}{*}{ Job } & Between Groups & 22.797 & 13 & 1.754 & 1.147 & .333 \\
\hline & Within Groups & 133.045 & 87 & 1.529 & & \\
\hline & Total & 155.842 & 100 & & & \\
\hline
\end{tabular}

According to table Since the total level of significance for the social statues and living and job is bigger than 0.05 , so we accept the hypothesis and conclude that " There is no statistically significant differences, in the significance level 0.05 , of use of traditional therapy according social statues and living and job ".
Correlation type:

Pearson

Number of rows used: 


\section{Correlations}

\begin{tabular}{|c|c|c|c|c|c|c|}
\hline & Good Reputation & Better Than & Leave Scar & Lack Trust & Rapid Healing & Cost \\
\hline better than & 0.072 & & & & & \\
\hline leaves car & -0.038 & 0.025 & & & & \\
\hline lack trust & -0.120 & 0.030 & 0.526 & & & \\
\hline rapid healing & 0.777 & 0.130 & 0.083 & -0.043 & & \\
\hline cost & 0.841 & 0.077 & 0.025 & -0.051 & 0.831 & \\
\hline no clinics & 0.101 & 0.092 & 0.293 & 0.357 & 0.151 & 0.190 \\
\hline advice elderly & 0.495 & -0.043 & 0.069 & -0.055 & 0.518 & 0.591 \\
\hline customs & 0.680 & -0.015 & -0.124 & -0.094 & 0.640 & 0.668 \\
\hline customs & 0.680 & -0.015 & -0.124 & -0.094 & 0.640 & 0.668 \\
\hline experience & 0.464 & 0.191 & 0.123 & 0.037 & 0.458 & 0.490 \\
\hline Freedom & -0.176 & 0.010 & 0.171 & 0.050 & -0.100 & -0.173 \\
\hline privacy & 0.713 & 0.143 & 0.032 & -0.047 & 0.711 & 0.784 \\
\hline privacy & 0.713 & 0.143 & 0.032 & -0.047 & 0.711 & 0.784 \\
\hline
\end{tabular}

We know that this study is the first population-based investigation to assess why traditional burning treatments are used in Palestine. A rise in the use of traditional and complementary medicine has worldwide been acknowledged as a broad demographic phenomena(Corner \& Harewood, 2004). Burn is one of the most prevalent issues of mankind in history, with consequences that can influence the physical, psychological, social and professional life of a person, therefore scientists and researchers have always noted the treatment of burns and complications. Most burn patients under 18 years accept these with Iranian research (Krishnamoorthy, Ramaiah, \& Bhananker, 2012), and Turkey (Tekin et al., 2012),(M. T. Qtait \& Alekel, 2018).

According to information to use $22 \%$ from participants, know from friends, $53.3 \%$ know from internet, 16.8 form media as radio and $\mathrm{TV}, 15 \%$ know from family, $7 \%$ from participants know from health care worker as physician and nurses. Friends/family and the internet were the most common sources of information traditional medicine. This suggests that the main sources of information are informal and unscientific, which may have consequences for the patients. It was interesting, however, to see that $7 \%$ of the use traditional medicine information about traditional medicine from health worker and physicians. This is the highest number reported so far in the literature as study (Swisher et al., 2002).

\section{Why use traditional therapy}

This study goal to know why people went to traditional therapy in burn, the first cause the traditional medicine because not leave scar post burn with percent $70 \%$, the result accept with study (Maden, Çalıkoğlu, \& Bodamyalızade, 2018). The second causes go to traditional therapy in burn as view of participants it's rapid healing with percent $67 \%$, this thought of people and most people think traditional therapy its nutrient as honey make rapid healing for this thought accept with study of (Dorai, 2012). The last cause it is not go to traditional therapy because there are no clinics near the home with percent $19 \%$ from our thought some Bedouins far from clinic but in city and village the clinic it's near.

The researcher divided causes why go to traditional therapy for three causes the first patient in burn not satisfaction with conventional medicine with percent $53 \%$, it's high and not accept with study (McFadden, Hernández, \& Ito, 2010) dissatisfaction from medicine showed a less clear relationship with traditional therapy use. People dissatisfaction from conventional medicine may be due to outcomes or medicine not successfully to treate burn without scar. or due to belief that natural remedies are safer and more effective than chemical drugs prescribed by doctor this accept with study (Siahpush, 1999), (Siahpush, 1998), (Holden, 1978).

Second main cause the patients' values, customs, percentage cultures Study of 43 percent Medical care attitudes and their capacity to understand, manage and cope with the course of a disease, the significance of the diagnosis, and the implications of medical treatment are affected by cultural variations. Patients and their families have cultural notions and values that are particular to health and sickness conceptions, symptom reporting, health care expectations, and drug- and treatment-related attitudes. Moreover, particular cultural values impact the responsibilities and expectations of patients, how much information is needed on disease and therapy. (McLaughlin \& Braun, 1998). The influence of culture on health is vast, it affects perceptions of health and in treatment of wound and burn in Palestine how illness and pain are experienced and expressed, where patients seek help, and the types of treatment patients prefer.

Third main cause Beliefs and think with percent $45.5 \%$, The study found personal health beliefs have effect on the use of traditional therapy in burn from view of researcher the people believe with traditional specially if build in Practical experiments between society, and that accept with study (Gyasi et al., 2016).

\section{Conclusion}

A thorough examination of why patients utilize trade treatment in burn in South West Bank was conducted in this study. 290 patients in 2020 with $29 \%$ of admissible treatment are admitted to burn unity in a Hebron Government Hospital. According to questionnaire used that divided to three section to know why use traditional therapy first dissatisfaction with conventional medicine with high percent $54 \%$, the second section The patients' values, customs with percent $46 \%$, and third section Beliefs and think $45 \%$.

For use can summary first for burn is convinced that traditional therapy is best than convention medicine, due not leave scarred and rapid healing based on experiment in. society and elderly.

Another explanations for using traditional medicine in burn think as philosophy no side effect for medication the mixture that uses from nature not contain chemical material, and thought the body its myself can use anything to treatment the body.

\section{Recommendations}


1. Information from studies can be used as a valuable complement to data from controlled clinical effectiveness research on traditional treatments.

2. The joint research efforts have the potential not just to modify certain forms of traditional biomedicine, but also to encourage greater conversation with the firm.

3. It is vital to understand why a large proportion of the population does not use mainstream biomedicine to treat a range of diseases and to maintain their overall health and wellness. Political leaders and health care experts still discuss improvements in the current system.

\section{Limitation of study}

The intersectional nature of the study prohibits us from reaching any judgment on the links between cause and effect.

Limitation for patient burn only not another patient use traditional therapy.

\section{References}

[1] Ahuja, R. B., \& Bhattacharya, S. (2004). Burns in the developing world and burn disasters. BMJ, 329(7463), 447-449.

[2] Astin, J. A. (1998). Why Patients Use Alternative Medicine Results of a National Study. JAMA, 279(19), 1548-1553. doi:10.1001/jama.279.19.1548.

[3] Bishop, F. L., Yardley, L., \& Lewith, G. T. (2008). Treat or treatment: a qualitative study analyzing patients' use of complementary and alternative medicine. American Journal of Public Health, 98(9), 1700-1705.

[4] De Smet, P. A. (1991). Is there any danger in using traditional remedies? Journal of Ethno pharmacology, 32(1-3), 43-50.

[5] Dorai, A. A. (2012). Wound care with traditional, complementary and alternative medicine. Indian journal of plastic surgery: official publication of the Association of Plastic Surgeons of India, 45(2), 418.

[6] Greenfield, E. (2010). The pivotal role of nursing personnel in burn care. Indian journal of plastic surgery: official publication of the Association of Plastic Surgeons of India, 43(Suppl), S94.

[7] Gyasi, R. M., Asante, F., Abass, K., Yeboah, J. Y., AduGyamfi, S., \& Amoah, P. A. (2016). Do health beliefs explain traditional medical therapies utilisation? Evidence from Ghana. Cogent Social Sciences, 2(1), 1209995.

[8] Holden, C. (1978). Holistic health concepts gaining momentum. Science, 200(4345), 1029-1029.

[9] Krishnamurthy, V., Ramaiah, R., \& Bhananker, S. M. (2012). Pediatric burn injuries. International journal of critical illness and injury science, 2(3), 128.

[10] Maden, S., Çalıkoğlu, E., \& Bodamyalızade, P. (2018). Herbal Therapy for Burns and Burn Scars. In Hot Topics in Burn Injuries: Intech Open.

[11] McFadden, K. L., Hernández, T. D., \& Ito, T. A. (2010). Attitudes toward complementary and alternative medicine influence its use. Explore, 6(6), 380-388.

[12] McLaughlin, L. A., \& Braun, K. L. (1998). Asian and Pacific Islander cultural values: considerations for health care decision making. Health \& social work, 23(2), 116126.

[13] Palestine, m. o. h. (2018). annual report Retrieved from

[14] Qtait, M., Alekel, K., \& Asfour, A. (2019). First Aid: Level of Knowledge of Relatives in Emergencies in Burn. International Journal of Biomedical and Clinical Sciences, 4(1), 24-28.

[15] Qtait, M., \& Asfour, A. WOUND INFECTIONS POST TRADITIONAL THERAPY AT A TERTIARY BURNS CENTER IN PALESTINE. Chest, 10, 20.

[16] Qtait, M. T., \& Alekel, K. (2018). Prevalence and epidemiological of burns in Hebron, Palestine. Sci J Clin Res Dermatol, 4(1), 001-005.

[17] Ray, P. H. (1997). The emerging culture. American Demographics, 19(2), 29-34.

[18] Siahpush, M. (1998). Postmodern values, dissatisfaction with conventional medicine and popularity of alternative therapies. Journal of Sociology, 34(1), 58-70.

[19] Siahpush, M. (1999). Why do people favour alternative medicine? Australian and New Zealand Journal of Public Health, 23(3), 266-271.

[20] Swisher, E. M., Cohn, D. E., Goff, B. A., Parham, J., Herzog, T. J., Rader, J. S., \& Mutch, D. G. (2002). Use of complementary and alternative medicine among women with gynecologic cancers. Gynecologic oncology, 84(3), 363-367.

[21] Tabish, S. A. (2008). Complementary and alternative healthcare: is it evidence-based? International journal of health sciences, 2(1), $\mathrm{V}$.

[22] Tekin, R., Yolbaş, İ., Selçuk, C. T., Güneş, A., Özhasanekler, A., \& Aldemir, M. (2012). An evaluation of pediatric burn patients a fifteen-years period. Turkish Journal of Trauma and Emergency Surgery, 18(6), 514518.

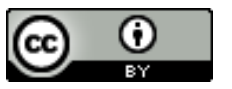

Open Access This article is licensed under a Creative Commons Attribution 4.0 International License, which permits use, sharing, adaptation, distribution and reproduction in any medium or format, as long as you give appropriate credit to the original author(s) and the source, provide a link to the Creative Commons license, and indicate if changes were made. The images or other third party material in this article are included in the article's Creative Commons license, unless indicated otherwise in a credit line to the material. If material is not included in the article's Creative Commons license and your intended use is not permitted by statutory regulation or exceeds the permitted use, you will need to obtain permission directly from the copyright holder. To view a copy of this license, visit https://creativecommons.org/licenses/by/4.0/.

(C) The Author(s) 2021 